\title{
Research on 2.45GHz active RFID card motion direction judgement algorithm based on RSSI distribution
}

\author{
Zhanbin Wang ${ }^{1, \text { a }}$, Tong Zhu', b, Haibo Zhang ${ }^{1, c}$ \\ ${ }^{1}$ Anti-counterfeiting Technology Division, The Third Research Institute of The Ministry of Public \\ Security of The P. R. C., Bisheng Road 339, Shanghai, China, 201204 \\ awzb_wzb_wzb@126.com, bfw339zt@126.com, cfw339zhb@126.com
}

\begin{abstract}
Keywords: Active RFID, Motion Direction Judgement Algorithm, RSSI Distribution, RFID Tag.
Abstract. In order to solve the problem that a large number tags motion direction judgement in campus long distance attendance system based on $2.45 \mathrm{GHz}$ active RFID technology, a technical test system was designed and constructed in this paper, the RSSI of the student tags through the technical test system obtained by two antennas. Then this paper analyzed the data characteristics, and proposed $2.45 \mathrm{GHz}$ active RFID card motion direction judgement algorithm based on RSSI distribution. Finally, 1000 student tags are used to experiment, and the experimental results shown that the effective judgment rate of the algorithm reaches more than $99.9 \%$.
\end{abstract}

\section{Introduction}

RFID (Radio Frequency Identification) is an emerging technology with many different applications, such as monitoring arm activity, indoor location and trajectory tracking [1-4]. In this paper, we introduce a campus attendance system using $2.45 \mathrm{GHz}$ active RFID technology, which can judge the direction of students entering and out of the campus with real time. In the early days, the technology systems were used for vehicle management in roads or parking lots [5, 6]. In the vehicle management system based on RFID technology, a RFID antenna is usually defined as 0 or A, and another RFID antenna is defined as 1 or $\mathrm{B}$, from 0 (A) to 1 (B) is in-state, from 1 (B) to 0 (A) is out-state. The construction environment of the active RFID technology system at the campus gate is significantly different from that of the road or parking door. At the same time, students walk in and out of the campus gate is also significantly different from roads and parking doors [7, 8]. Therefore, the algorithms based on simple Boolean operations to determine vehicle access or vehicle movement direction are not applicable at school gates. Due to the influence of the campus gate buildings, the RFID technology system cannot get the ideal RF coverage as roads. The number of students entering and leaving campus is also much more complicated than the vehicles on roads. In fact, some schools introduced the RFID technology attendance system using Boolean algorithm, have happened a large number of missing cards, and wrong direction results $[9,10]$. In order to make the active RFID technology attendance system more effective in the school gate, this paper proposes an algorithm of the active card motion direction judgement algorithm based on the RSSI (Received Signal Strength Indication) distribution.

\section{Design and construction of test system}

According to the requirements of campus long-distance attendance, a remote attendance system based on $2.45 \mathrm{GHz}$ active RFID was designed. Shown as figure 1, the sketch map of campus attendance system include two antennas and a data processing equipment. The two antennas are fixed outside the school and inside the school, the antenna outside the school is A, and the antenna inside the school is B. The two antennas are connected to the data processing equipment through the network cable. The data processing equipment is located inside the school gate building. The data processing equipment acquires data from two antennas and provides electricity to two antennas. The $2.45 \mathrm{GHz}$ active RFID information include ID number, RSSI, and real time, this information is transmitted once a second. The direction of the RFID card is judged in the data processing terminal. Finally, we constructed the 
actual campus attendance system according to the sketch map of campus attendance system based on $2.45 \mathrm{GHz}$ active RFID. Shown as figure 2, we contacted a school and installed two $2.45 \mathrm{GHz}$ active RFID antennas inside and outside school, and the data processing equipment was installed inside the school gate building.

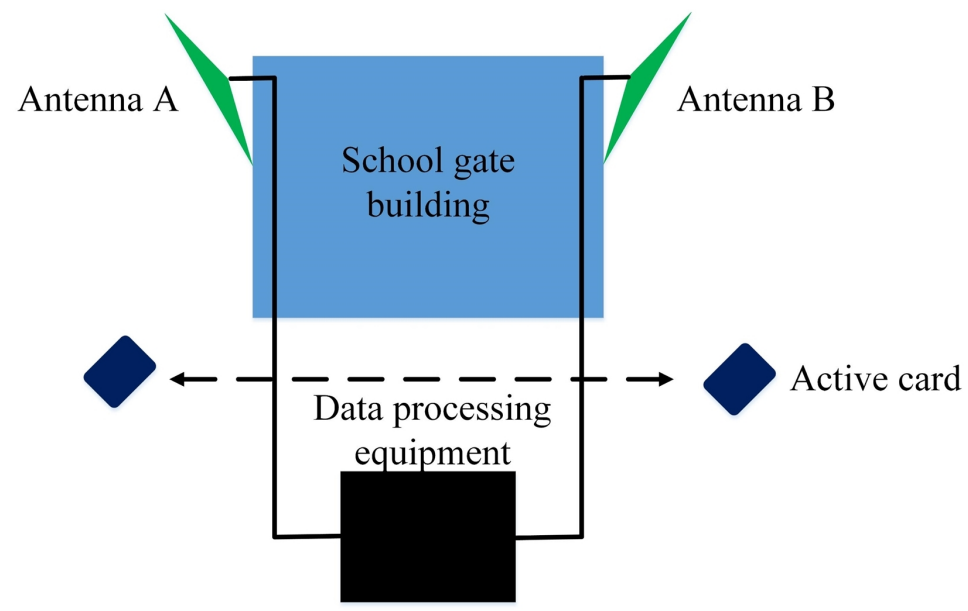

Fig. 1 The sketch map of campus attendance system based on $2.45 \mathrm{GHz}$ active RFID

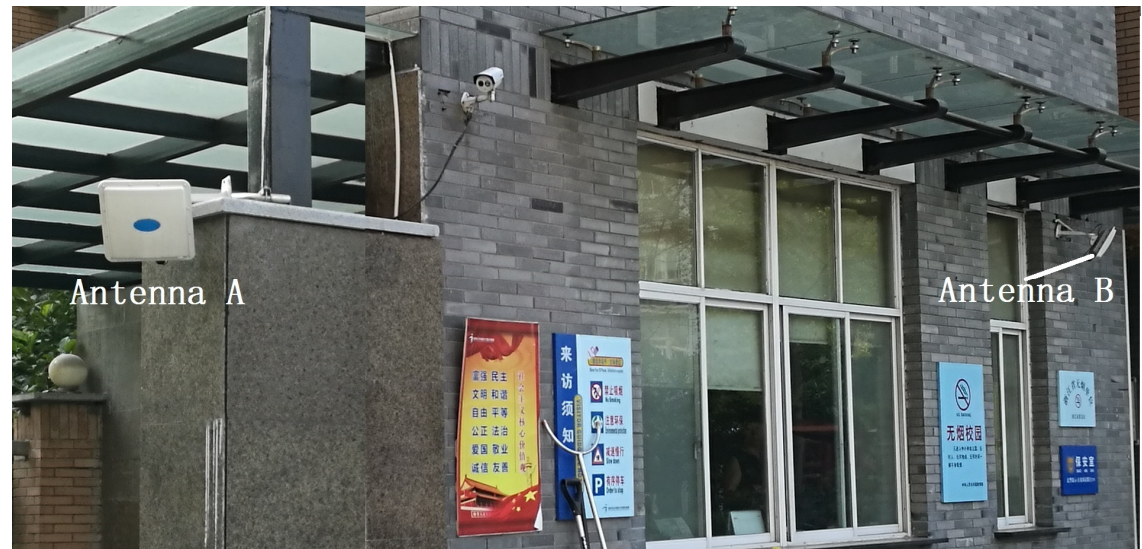

Fig. 2 The physical map of campus attendance system based on $2.45 \mathrm{GHz}$ active RFID

\section{Data feature analysis and algorithm design}

Based on the design and construction of the test system, we can get the microwave coverage area shown in Figure 3 according to the RFID principle. Although the school gate building has a certain isolation effect, but the cross area of the two antennas is difficult to exclude for various reasons. And because of the uncertainty of the school gate building and the reasons for the absorption and reflection of the ground, the microwave cross area is irregular. Therefore, we can infer that when the $2.45 \mathrm{GHz}$ active RFID card enters the school gate, the RSSI received by the two antennas are nonlinear, even catastrophic and hopping.

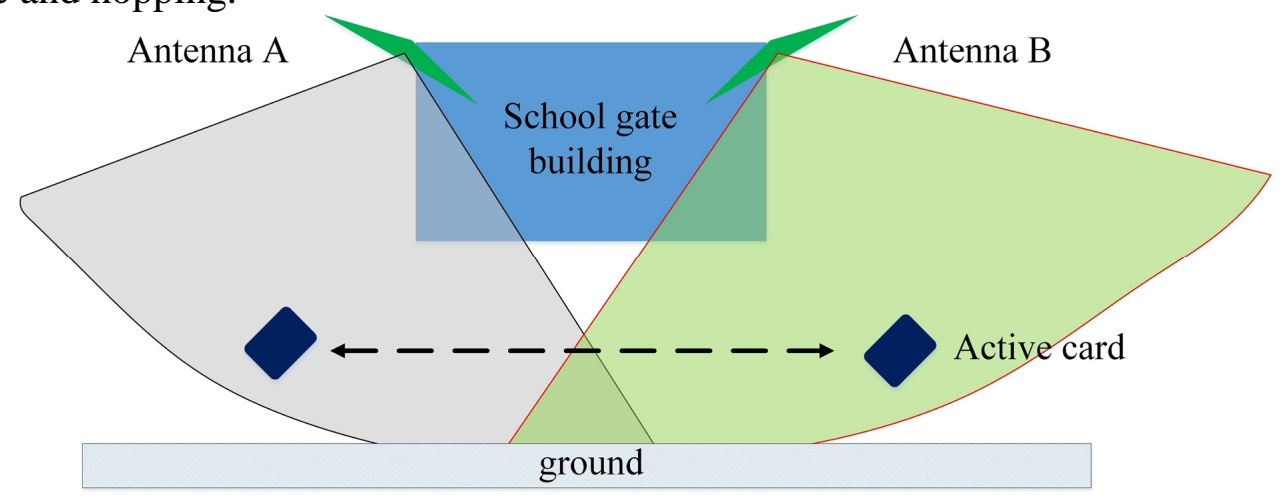

Fig. 3 The sketch map of microwave coverage of RFID reader 
In order to judge the direction of the $2.45 \mathrm{GHz}$ active RFID card, a set of experimental data must be obtained to observe the RSSI waveform, so as to design a targeted direction judgment algorithm. Shown as figure 4, a set of data is obtained from the test system. We can find that the data of antenna A or antenna B obey the Gauss distribution basically, and the data process is nonlinear, even mutagenesis and jumping. There is a cross area between the antenna $\mathrm{A}$ and the antenna $\mathrm{B}$, and the intersecting area of the antenna B is larger. The maximum value of antenna A or antenna B basically occurs under $2.45 \mathrm{GHz}$ active RFID tag passing through the antenna. The maximum value of the test tag RSSI obtained by the antenna $\mathrm{A}$ is -75 , and the maximum value of the test tag RSSI obtained by the antenna B is -78 . The minimum value of the test tag RSSI obtained by the antenna A is -104 , and The minimum value of the test tag RSSI obtained by the antenna B is -105 .

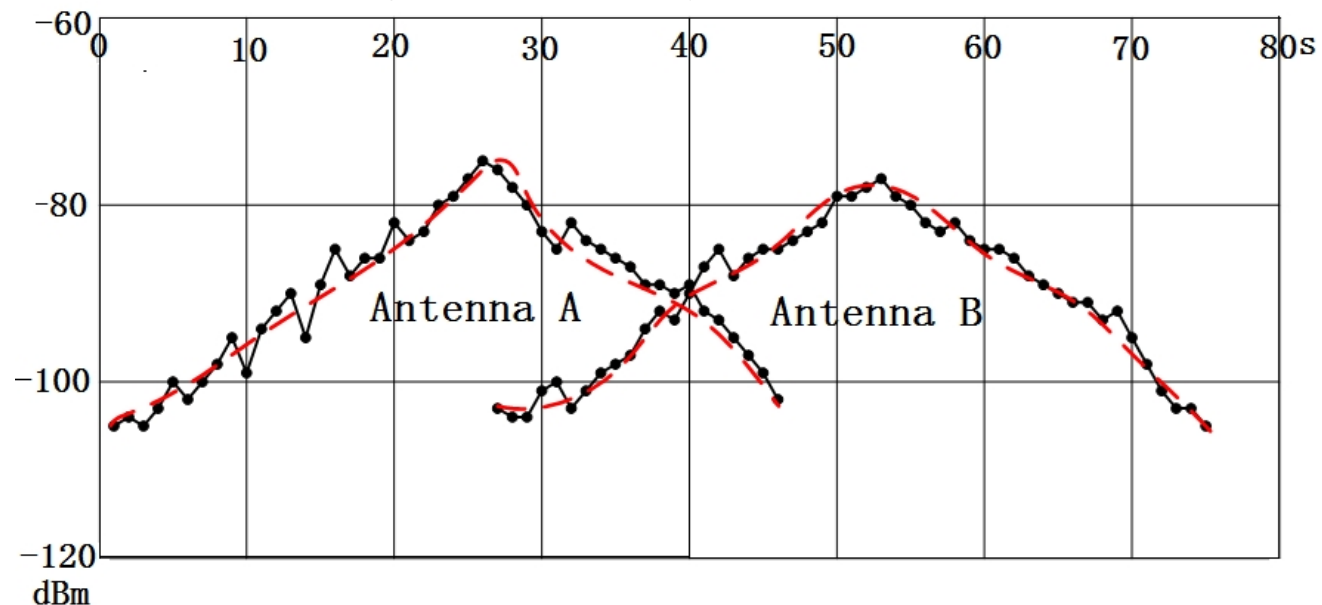

Fig. 4 The RSSI distribution of the RFID tag passing through the school gate

On the other hand, we design the algorithm, must consider that the students detention at the school gate long time, in a microwave area of an antenna or in the overlapping area of the two antennas. At the same time, we should also consider the abnormal situation that students return to the microwave area for a short time after they leave the microwave area. We find that there is a rule that can be used to judge the direction of the tag motion, which is the antenna that tag passes first to get the average peak value early, and finally the peak time of the average line can be used to judge the direction of the tag. This method is stable in theory, and avoids the difference of the shape of the average lines, evading the processing of the overlap area of the signal, and even the large overlap area of the signal will not cause the error of judging the direction of the entry and exit.

The input variables of the tags direction judgment algorithm we defined are the RFID tag ID, RSSI, and real time that the two antennas obtained. The output variables of the tags direction judgment algorithm are the three direction states of RFID tag, that is in-state, out-state and detention-state, and the real time of occurrence of events. The flow chart of the tags direction judgment algorithm is shown in Figure 5.

1. The first step: determine the trigger condition of the algorithm.

if (Time_Clock_Now - Time_ D_New) $>30$ s

then start directionjudgment algorithm

else (Time_D_New-Time_D_Old) > 30Minute

output detention-state

2. The second step: the amount of data obtained from each card is less than 5.

if (No. of data $\leq 5)$

then simple mean filtering

3. The third step: the amount of data obtained from each card is more than 5 .

if $($ No. of data $>5)$

then sliding mean filtering 


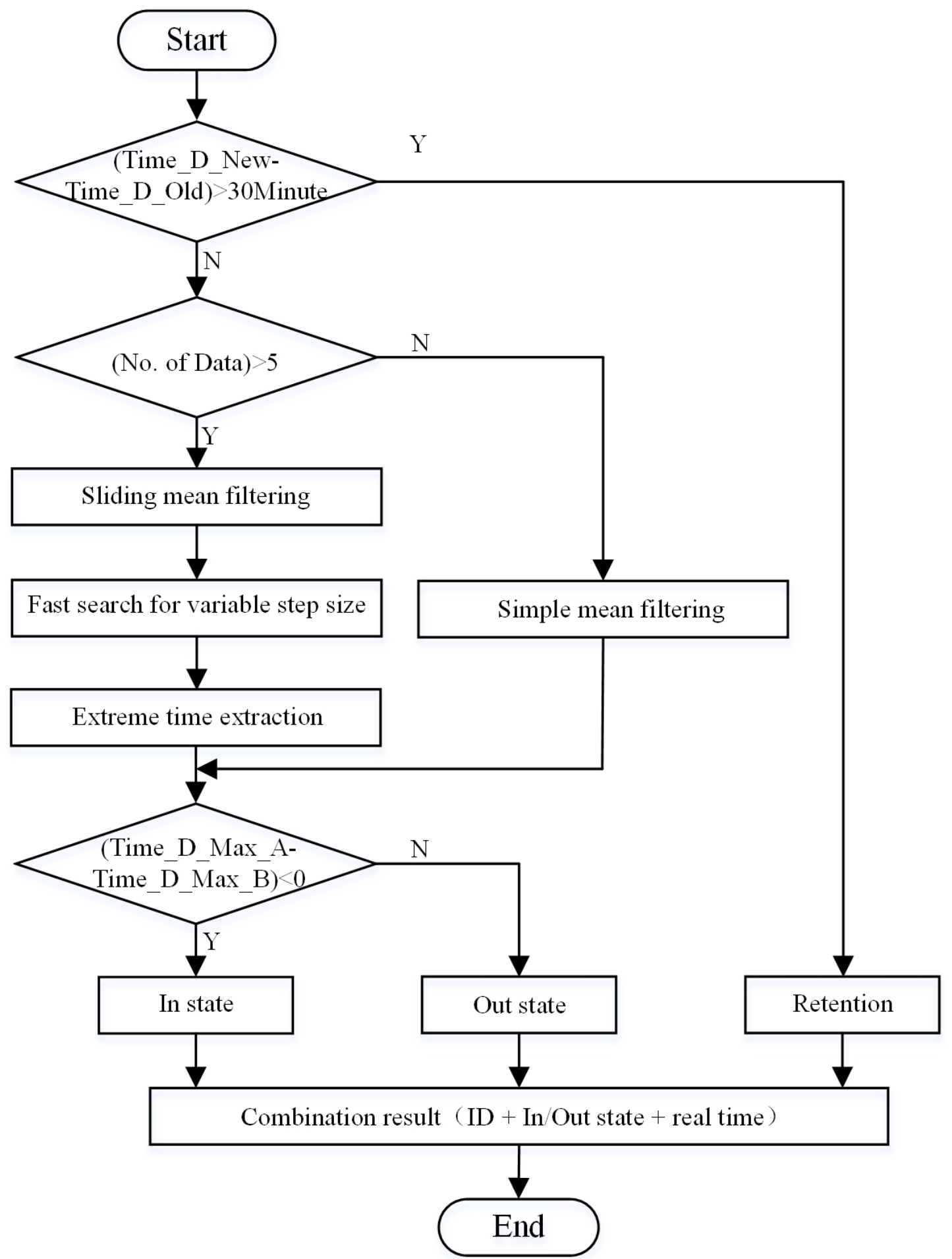

Fig. 5 Flow chart of algorithm

Assume that the tag data obtained by any antenna is a two-dimensional array:

$$
\left[D_{0}\left(\text { ISSI }_{0}, \text { Time }_{0}\right), D_{1}\left(\text { ISSI }_{1}, \text { Time }_{1}\right) \mathrm{L} D_{n-1}\left(\text { ISSI }_{n-1}, \text { Time }_{n-1}\right)\right]
$$

Select the width of the sliding window for 5 data:

$$
\left[D_{i-2}, D_{i-1}, D_{i}, D_{i+1}, D_{i+2}\right], D_{i}, 2 \leq i \leq n-3
$$

Ascending order according to the RSSI:

$$
\begin{gathered}
{\left[D_{0}, D_{1}, D_{2}, D_{3}, D_{4}\right]} \\
D_{i}=\frac{D_{1}+D_{2}+D_{3}}{3}
\end{gathered}
$$


For $D_{i}, i=0,1, n-2, n-1$ :

$$
\left[D_{-2}, D_{-1}, D_{0}, D_{1}\left\llcorner D_{n-1}, D_{n}, D_{n+1}\right], D_{-2}=D_{-1}=D_{0}, D_{n-1}=D_{n}=D_{n+1}\right.
$$

Finally, $\left[D_{0}\left(\overline{I S S I}_{0}\right.\right.$, Time $\left._{0}\right), D_{1}\left(\overline{I S S I}_{1}\right.$, Time $\left._{1}\right) \mathrm{L} D_{n-1}\left(\overline{I S S I}_{n-1}\right.$, Time $\left.\left._{n-1}\right)\right]$ can be obtained.

4. The fourth step: the maximum value search by variable-step.

Suppose the starting search step is 3 data:

$$
\begin{aligned}
& {\left[D_{0}\left(\overline{\text { ISSI }}_{0}, \text { Time }_{0}\right), D_{1}\left(\overline{\text { ISSI }}_{1}, \text { Time }_{1}\right) \mathrm{L} D_{n-1}\left(\overline{\text { ISSI }}_{n-1}, \text { Time }_{n-1}\right)\right]} \\
& D_{\text {temp }}=D_{i} \\
& \text { if }\left(D_{\text {temp }}<D_{i+3}\right), 0 \leq i \leq n-1 \\
& D_{\text {temp }}=D_{i+3} \\
& \text { if }\left(D_{\text {temp }}>D_{i+3}\right) \\
& D_{i}=D_{\text {temp }}
\end{aligned}
$$

Find a larger value $D_{i}$

Modify the search step length to 1 data:

Then find the maximum from $\left[D_{i-2}, D_{i-1}, D_{i}, D_{i+1}, D_{i+2}\right], D_{j}, 0 \leq j \leq 4$

5. The Fifth step: extreme time extraction.

$$
\text { Time }_{j}=D_{j}\left(\text { ISSI }_{j}, \text { Time }_{j}\right)
$$

6. The sixth step: the tags direction judgment.

$$
\begin{aligned}
& \text { if }\left(\text { Time }_{j}<\text { TimeB }_{j}\right) \\
& \text { then in-state } \\
& \text { else out-state }
\end{aligned}
$$

\section{Experimental data analysis and conclusions}

The experiment used 1000 RFID tags, and implemented ten tests, including 5 times entered school and 5 times depart from school, and the results were shown in table 1 . The test results showed that 7 times $100 \%, 3$ times $99.9 \%$, no test result was less than $99.9 \%$, and the test success rate was more than 99.9\%.Three conclusions can be obtained from the experimental results: 1 . the design of the test system and the construction of the actual system were effective; 2 . data feature analysis was reliable; 3 . the $2.45 \mathrm{GHz}$ active RFID card motion direction judgement algorithm based on RSSI distribution was practical.

Table 1 The experimental results

\begin{tabular}{ccc|ccc}
\hline In & Results & Success rates & Out & Results & Success rates \\
\hline 1 & 1000 & $100 \%$ & 1 & 999 & $99.9 \%$ \\
2 & 1000 & $100 \%$ & 2 & 1000 & $100 \%$ \\
3 & 999 & $99.9 \%$ & 3 & 1000 & $100 \%$ \\
4 & 1000 & $100 \%$ & 4 & 1000 & $100 \%$ \\
5 & 1000 & $100 \%$ & 5 & 999 & $99.9 \%$ \\
\hline
\end{tabular}




\section{Acknowledgements}

In addition to the contribution of the relevant team members of the Anti-counterfeiting Technology Division of the TRIMPS (The Third Research Institute of The Ministry of Public Security of The P. R. C.), also thanks to Lihua Chen of the Special technology Division of the TRIMPS for her advice during the research process. As well as the contribution of Shanghai Fei-xu Electronic Equipment Co., Ltd. and Shanghai Fei-chen Electronic Technology Co., Ltd. for their user relationship during the construction of test system.

\section{References}

[1] B. Joydip, U. Gitendra, S. Nilanjan, et al. "Sensor-enabled RFID System for Monitoring Arm Activity: Reliability and Validity", IEEE Transactions on Neural Systems and Rehabilitation Engineering, Vol. 20, No. 6, p. 771-777, 2012

[2] Y. Alvarez, F. Las Heras, "ZigBee-based sensor network for indoor location and tracking applications", IEEE Latin America Transactions, Vol. 14, No. 7, p. 3208-3214, 2016

[3] J.H. Oh, D. Kim, B.H. Lee, “An indoor localization system or mobile robots using an active infrared positioning sensor", Journal of Industrial and Intelligent Information, Vol. 2, No. 1, p. $35-38,2014$

[4] L. M .Ni, Y.H. Liu, Y.C. Lau, A.P. Patil, "LANDMARC: Indoor Location Sensing Using Active RFID", Proceedings of the 1st IEEE International Conference on Pervasive Computing and Communications, p.407-415, 2003

[5] A.G. Foina, S.E. Barbin, F.J. Ramirez, "A New Approach for Vehicle Access Control Using Active RFID Tags", SBMO/IEEE MTT-S International Microwave and Optoelectronics Conference Proceedings, p.90-93, 2007

[6] E.Z. Zhang, Y.J Kuang, W.L. Jiang, M.A. Umer, “Active RFID Positioning of Vehicles In Road Traffic", 11th International Symposium on Communications and Information Technologies, p.222-227, 2011

[7] H.T. Song, Y.L. Zhao, H.Y. Lan, "Multi-channel active RFID system for IoT application", Proceedings of 2012 International Conference on Measurement, Information and Control, p. $568-571,2012$

[8] K. Herdawatie Abdul, W. Mohd Helmy Abd, T. Zarina, M. Ariffin Abdul, "Tracking Student Movement Using Active RFID", Proceedings of the 9th WSEAS International Conference on Applications of Computer Engineering, p.41-45, 2010

[9] K. Hashizume, S. Kaneda, H. haga, "Direction Detection Method Using Active RFID", Proceedings of the 6th IASTED International Conference on Web-Based Education, p.615-620, 2007

[10]J. Yu, W. Yang, Y. Zhang, "Estimating the Direction of Motion Based on Active RFID", Proceedings - 5th International Conference on New Trends in Information Science and Service Science, p.286-290, 2011 